\title{
Scholarship in Indonesia: the crossing between digital vs neanderthal mind
}

\author{
Dasapta Erwin Irawan ${ }^{1}$ \\ 1 Ins titut Teknologi Bandung \\ Funding: The author(s) received no specific funding for this work. \\ Potential competing interests: The author(s) declared that no potential competing interests exist.
}

\begin{abstract}
Here are my key points in my panel talk in this event Digital Scholarship \& Open Access, organized by NUS, held on 15 July 2020 (link to my blog:

http://dasaptaerwin.net/wp/2020/07/digital-scholarship-open-access.html).
\end{abstract}

\section{How does open access start?}

Open Access (OA) has started way back in 1990's. Project Gutenberg and ERIC were two famous examples of knowledge sharing in early days of open access (minus the internet). Years prior, in 1960's people have been trying to connect computers, to make them talk to each other. The internet (ARPHANET) was first launched to overcome access and structural constraints of communications. And now, those computers are US.

How has open access evolved?

It grows to common digital scholarship

- Digital scholarship means knowledge creation, knowledge sharing, knowledge preservation - repeat.

- Digital scholarship also means: upstream to downstream connectivity, since research, to publication, to communication. It would need a mind shifting from analog to digital where all must be registered (so it can be searched).

- Communication includes digital teaching materials and digital communication on social media. Instant and spontaneous conversation vs deep carefully crafted conversation.

- IP problems with digital materials. Copyrighting and fair use.

- Relates to infrastructure and who's in charge for maintenance and sustainable funding. Sustainable form has not be clearly defined due to local values. 
Challenges

- network/access (plays for both ends: researcher as producers and researcher as users),

- language barrier (English-centric),

- skill in research and how to use available technology (related to no 1 and 2),

- policy that drives perception of quality (Western-centric),

- incentives (build upon no 4).

Available technologies

- free communication platforms (Whatsapp, Telegram, Slack, Google Mail/Miling list, etc),

- open source publishing platforms (OJS from PKP), Eprints from Soton,

- university resource sharing

Digital scholarship landscape in Indonesia

- infrastructure (academic journals): 1600+ academic journals, most of them are using open source journal management platform (eg: OJS from PKP), minimally funded by institutional budget.

- infrastructure (institutional repository): 137 IR (opendoar.org), most of them are using open source repository management platform (eg: Eprints, Dspace, and Dataverse).

- supporting components: Avid journal managers association, journal accreditation, etc

- IRs connected to ONEsearch from Perpusnas (National Library). Academic journals connected to GARUDA database. Discoverable is not the main problem here.

- RIN hosted by Indonesia Science Foundation (LIPI). Data repository is also recently available, for common academics and researchers to share their data.

- Aside to the what is available, on the other hand we have performance (research and staff) measurement platforms that are built upon centralized regulations (SINTA and Promotion System) and backed up by commercial entities (eg: Scopus and Web of Science) as the standard of quality.

\section{How it all relates to the Neanderthals?}

- Homo neanderthalensis or Homo sapiens neanderthalensis)[8] are an extinct species or subspecies of archaic humans who lived in Eurasia until about 40,000 years ago. Neanderthal technology is thought to have been quite sophisticated.

- Neanderthal archaic humans were used to describe a modern community at that time has all the resources but refuse to develop with the advancement of current technology.

- setting up own boundaries and walls that has led to the dwarfing of academic minds. 
- such dwarfing has also led to the decreasing sensitivity to surrounding problems and hidden research potential (eg: wayang by Miguel Escobar Varela).

- misconception of globalization and internationalization as a fierce competitive world, whereas the actual condition now is embracing collaboration.

- another problem by far (not only for Indonesia, but the globe as whole) is commercialization in academic outputs. Copyrights transfer agreement has been the major obstacle for academic to share their results from the smallest fragments (eg: figure, photograph, plots), to the biggest chunk (eg: ideas/proposed solutions for the on going societal problem. Fair use has been made as a rubber clause to prevent further access. It's worsened by the low researcher's awareness of the basics of IPR. 